\title{
Surgical Successful Treatment of Cushing's Syndrome in a Pregnant Patient Complicated with Severe Cardiac Involvement
}

\author{
Yoshinobu KAMIYA, MASAMI OKADA, AKIHIKo YONEYAMA, YASUNARI JIN-NO, \\ TAKESHI HIBINO, OsAMU WATANABE*, SHOJI KAJIURA*, YoshIKATSU SUZUKI*, \\ HIROJI IWATA** AND SYUNZO KOBAYASHI** \\ Third Department of Internal Medicine, *Department of Obstetrics and Gynecology, \\ **Second Department of Surgery, Nagoya City University Medical School, Nagoya 467-8601, Japan
}

\begin{abstract}
We encountered a case of a pregnant woman with adrenal causes of Cushing's syndrome who exhibited congestive heart failure as an initial symptom. Since the patient was also a diabetic, we treated her with high levels of diuretics and insulin. Echocardiography revealed a remarkable thickening of the left ventricle without asymmetric hypertrophy. The diagnosis of Cushing's syndrome caused by adrenal adenoma was confirmed by the endocrinological data and magnetic resonance imaging. The right adrenal adenoma was removed in the 28th week of pregnancy. After the operation, her congestive heart failure and hyperglycemia dramatically improved. Five weeks after the operation, she delivered a normal infant by caesarean section without complications. Only 4 months after delivery, the thickening of her left ventricle was normalized. We consider that the progression of her left ventricular hypertrophy induced by the changes in hemodynamic load during pregnancy may have been augmented by the excess of plasma cortisol. Operative therapy may be recommended for pregnant Cushing's syndrome patients with severe hypercortisolism complicating congestive heart failure.
\end{abstract}

Key words: Cushing's syndrome, Adrenal tumor, Pregnancy, Left ventricular hypertrophy

(Endocrine Journal 45: 499-504, 1998)

THE occurrence of pregnancy in the face of untreated Cushing's syndrome is rare because of the high incidence of ovulatory disturbances experienced by patients with the disorder [1-3]. When Harvey Cushing described his syndrome in 1932, he named it the "killing disease" because of its cardiovascular complications [4,5]. It was reported that the inter ventricular septum in Cushing's syndrome was extremely thick and asymmetric septal hypertrophy occurred more often than essential hypertension [6-8]. We encountered

Received: December 2, 1997

Accepted: March 20, 1998

Correspondence to: Dr. Yoshinobu KAMIYA, Third Department of Internal Medicine, Nagoya City University Medical School, 1-Kawasumi, Mizuho-cho, Mizuho-ku, Nagoya 467-8601, Japan a pregnant patient with untreated Cushing's syndrome caused by adrenal adenoma who manifested left ventricular heart failure probably due to wall thickening of the left ventricle. Nakayama et al. summarized the previously reported 97 cases of pregnant women with Cushing's syndrome and discussed the prognosis of pregnant women and their fetus [9]. They reported that 83 patients among these cases were not treated for hypercortisolism, but that patients with severe hypercortisolism in the second trimester of pregnancy were recommended for surgical treatment. It is difficult to determine the treatment for a pregnant woman with Cushing's syndrome who has severe hypercortisolism, which complicates the high risk for surgical treatment such as left ventricular heart failure. 


\section{Case Report}

A 29-year-old pregnant Japanese woman was transferred to our hospital on August 10, 1996 because of congestive heart failure. She had a past history of intra-uterine fetal death 28 months before admission when her hyperglycemia, hypertension and wall thickening of the left ventricle was diagnosed. Thereafter her hyperglycemia and hypertension were stabilized by diet therapy alone. Eighteen weeks before admission, in the 6th week of her second pregnancy, she was admitted to another hospital to control the level of blood glucose and hypertension. She was treated with insulin and anti-hypertensive agents. In the 22rd week of the pregnancy, she experienced progressive dyspnea. She was treated with dopamine, digoxin and oxygen for a presumptive diagnosis of pulmonary congestion due to left-sided heart failure. In the 24th week of pregnancy, she was transferred to our hospital because there had been no improvement in her congestive heart failure.

Physical examination on admission revealed that her blood pressure was $142 / 92 \mathrm{mmHg}$ and her pulse was $120 \mathrm{bpm}$ and regular, her body temperature was $37.0{ }^{\circ} \mathrm{C}$, her skin was thin and several ecchymoses were found. Red-purple striae were found on her abdominal skin. The muscles of the extremities were atrophic. No moon face or buffalo hump was found. The optic fundus examined by an ophthalmologist was normal.

The RBC count was $2.73 \times 10^{6} / \mu l$, WBC $12.0 \times$ $10^{3} / \mu l$ (eosinophil $0.3 \%$ ) and platelets $26.7 \times 10^{4} /$ $\mu l$. The serum level of total protein was $6.6 \mathrm{~g} / \mathrm{dl}$, albumin $4.5 \mathrm{~g} / \mathrm{d} l$, AST $16 \mathrm{U} / l$, ALT $18 \mathrm{U} / l$, LDH $131 \mathrm{U} / l$, sodium $135 \mathrm{mEq} / l$, potassium $3.3 \mathrm{mEq} / l$, BUN $18 \mathrm{mg} / \mathrm{d} l$, CRP $0.2 \mathrm{mg} / \mathrm{d} l$, fasting plasma glucose $110 \mathrm{mg} / \mathrm{d} l$ and $\mathrm{HbA} 1 \mathrm{c} 5.0 \%$. Blood gas analysis on nasal administration of oxygen (4 1/ min) showed that $\mathrm{PaO}_{2}$ was 85.5 torr and $\mathrm{PaCO}_{2}$ 18.7 torr. The plasma level of cortisol was high without circadian rhythm, and ACTH was not detectable. The other endocrinological data are shown in Table 1.

X-ray film of the chest showed a diffuse reticulonodular shadow in the lung fields and an enlargement of the cardiac silhouette, suggesting pulmonary congestion due to congestive heart failure. Electrocardiography showed a normal
Table 1. Endocrinological data

\begin{tabular}{lrl}
\hline cortisol $(0700 \mathrm{~h})$ & $70.0 \mu \mathrm{g} / \mathrm{d} l$ & $(3.0-15.2)$ \\
cortisol $(1100 \mathrm{~h})$ & $76.5 \mu \mathrm{g} / \mathrm{d} l$ & \\
ACTH & $<0.03 \mathrm{pg} / \mathrm{ml} l$ & $(6-36)$ \\
PRA & $22.0 \mathrm{ng} / \mathrm{ml} \cdot \mathrm{h}$ & $(0.3-2.9)$ \\
PAC & $6 \mathrm{ng} / \mathrm{d} l$ & $(3-16)$ \\
$\mathrm{TSH}$ & $0.75 \mu \mathrm{IU} / \mathrm{ml} l$ & $(0.35-3.73)$ \\
free T3 & $1.8 \mathrm{pg} / \mathrm{ml} l$ & $(2.2-4.1)$ \\
free T4 & $0.8 \mathrm{ng} / \mathrm{d} l$ & $(0.82-1.67)$ \\
$\mathrm{HPL}$ & $5.44 \mu \mathrm{g} / \mathrm{ml}$ & $(3.0-9.9)$ \\
$\mathrm{IGF}-\mathrm{I}$ & $89.7 \mathrm{ng} / \mathrm{ml} l$ & $(121-436)$ \\
$\mathrm{u}-$-free cortisol & $958.5 \mu \mathrm{g} / \mathrm{day}$ & $(35-150)$ \\
$\mathrm{u}-17-O H C S$ & $10.9 \mathrm{mg} / \mathrm{day}$ & $(1.9-6.1)$ \\
$\mathrm{u}-17-K S$ & $5.1 \mathrm{mg} / \mathrm{day}$ & $(3.1-8.8)$ \\
u-C-peptide & $57.8 \mu \mathrm{g} / \mathrm{day}$ & $(20-130)$ \\
\hline
\end{tabular}

$\mathrm{u}$, indicates urinary; PRA, plasma renin activity; PAC, plasma aldosterone concentration; HPL, human placental lactogen; IGF-I, insulin like growth factor-I.

rhythm at a rate of 95 with high voltage and an inverted T-wave in V1 V6 (Fig. 1c). An Echocardiography study revealed a thick-walled, dilated ventricle. Both the inter ventricular septum and the free wall were $25 \mathrm{~mm}$ in thickness. There was no dyskinesis of the left ventricle, and the ejection fraction was $65 \%$ (Fig. 1a).

She was treated with an administration of oxygen and $40 \mathrm{mg}$ Furocemide i.v. for her heart failure and with a subcutaneous insulin infusion for her hyperglycemia. The manifestation of heart failure gradually improved resulting in no occurrence of dyspnea at rest, but it recurred under minor exertion. The plasma level of glucose was well controlled by multiple subcutaneous insulin infusions. The dose of insulin required to control the plasma glucose gradually increased to $100 \mathrm{IU}$ per day in the 25th week of pregnancy. The diagnosis of Cushing's syndrome was confirmed by the finding of a noticeable increase in serum and urinary cortisol concentrations with a loss of the normal circadian rhythm of serum cortisol. Plasma ACTH was undetectable. Magnetic resonance imaging of the adrenals revealed a homogeneous nodule in the right adrenal region with high intensity on a T2 weighted image of the liver (Fig. 2). After explaining of the surgical treatment for Cushing's syndrome and the prognosis of our patients and her fetus, informed consent was obtained. The adrenalectomy by transflank-approached surgery was performed on 


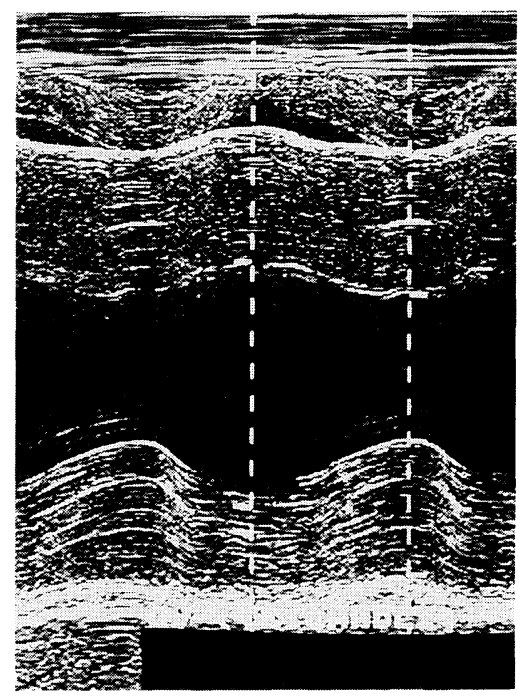

(a)

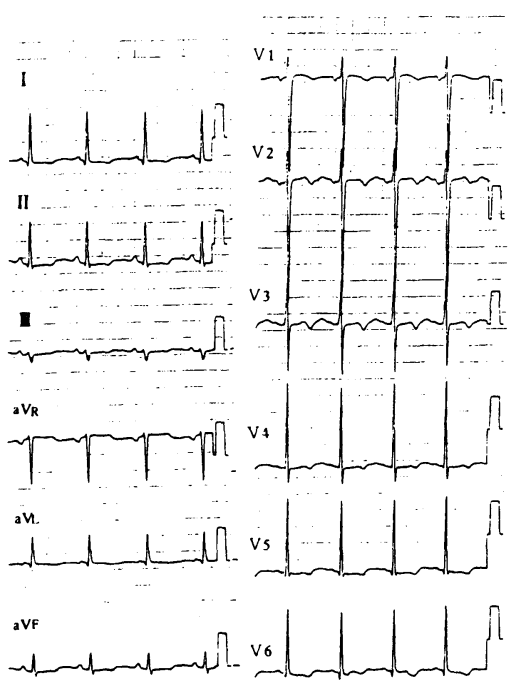

(c)

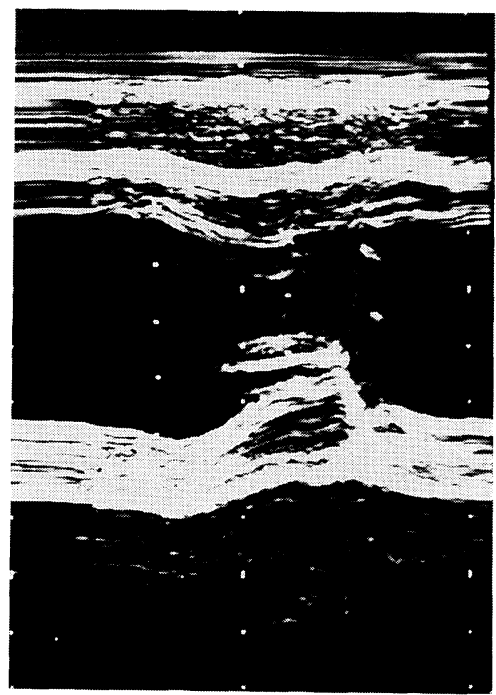

(b)
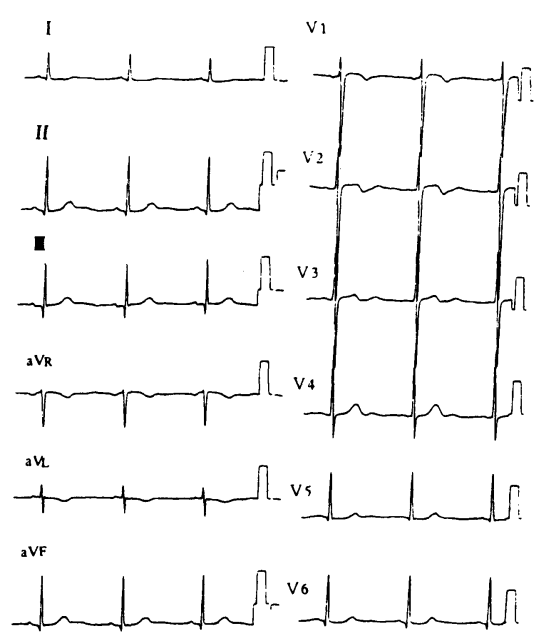

(d)

Fig. 1. Echocardiography and electrocardiography on admission and after delivery. An echocardiography study on admission (a) revealed a thick-walled, dilated ventricle. Both the interventricular septum and the free wall were $25 \mathrm{~mm}$ thick. An electrocardiographical study on admission (c) showed a normal rhythm at a rate of 95 with high voltage (sV1: 3.0 $\mathrm{mV}, \mathrm{rV} 5: 2.3 \mathrm{mV}$ ) and an inverted T-wave in V1 V6. An echocardiography 4 months after delivery (b) showed no abnormal findings. The voltage in an electrocardiography 4 months after delivery (d) decreased (sV1: $2.4 \mathrm{mV}, \mathrm{rV5}: 1.4 \mathrm{mV}$ ).

day 3 of the 28th week of pregnancy (Fig. 3).

Postoperatively the patient made an uncomplicated recovery; and $200 \mathrm{mg}$ replacement of hydrocortisone was started. We gradually decreased the replacement dose to $20 \mathrm{mg}$ of hydrocortisone until delivery. The dose of insulin to control the plasma glucose level dramatically decreased to zero 18 days after surgery. Her 


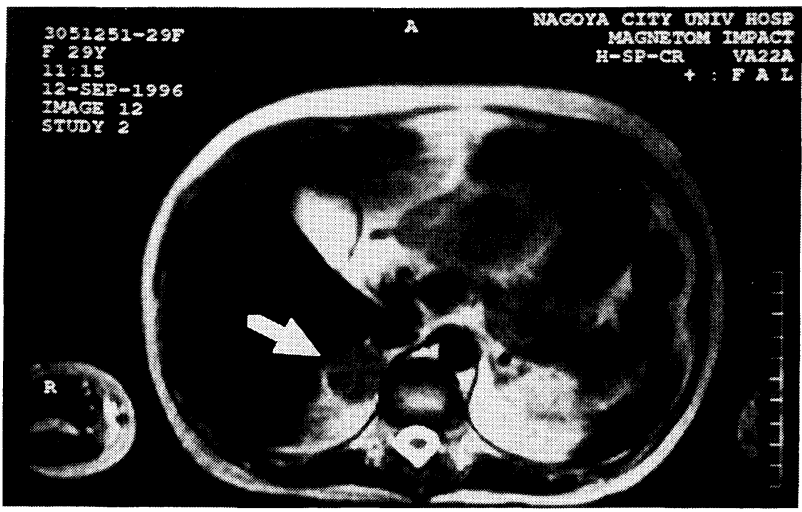

Fig. 2. Magnetic resonance image of abdomen. Magnetic resonance imaging of the adrenals revealed a homogeneous nodule in the right adrenal region with high intensity on a T2 weighted image of the liver. The arrow indicates the right adrenal mass.

congestive heart failure improved, and the $\mathrm{PO}_{2}$ level was normalized without oxygen administration. A Caesarean section was performed in the 33rd week of pregnancy because of premature rupture of her membrane and a female infant was delivered. The body weight and apgar score of the infant were $1744 \mathrm{~g}$ and 9, respectively. The level of ACTH in the infant was $18 \mathrm{pg} / \mathrm{ml}$. One hundred $\mathrm{mg}$ of hydrocortisone per day was added to that administered before the Caesarean section. We could control the heart failure without medications such as Frocemide 10 days after the Caesarean section (Fig. 3).

Four months after delivery, the wall thickening of the left ventricle was normalized (Fig. 1b), and the abnormality in electrocardiography disappeared. Furthermore, no glucose intolerance has been observed in a recent study.

\section{Discussion}

A pregnant patient with Cushing's syndrome due to an adrenal adenoma who was diagnosed in the second trimester is described.

The diagnosis of Cushing's syndrome during pregnancy is complex because the biochemical features are obscured by changes in the normal hypothalamo-pituitary-adrenal axis or the excessive production of corticosteroid binding globulin that occur during gestation $[10,11]$. The diagnosis was

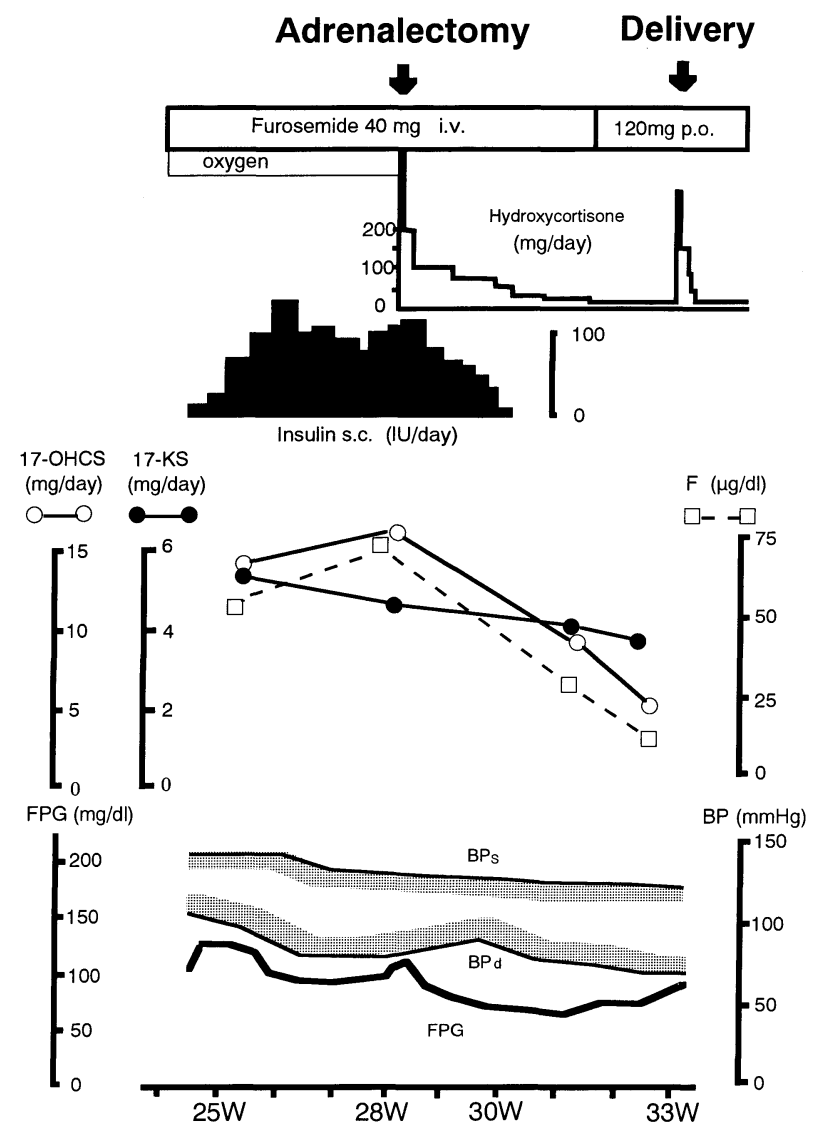

Fig. 3. Clinical course of pregnant patient with Cushing's syndrome after admission to our hospital. u-, urinary; F, plasma cortisol; FPG, fasting plasma glucose.

possible because of the typical physical findings of Cushing's syndrome and the noticeable increase in urinary 17-OHCS and the lack of a plasma cortisol circadian rhythm. The onset of Cushing's syndrome in our patients is obscure. The hyperglycemia, hypertension and wall thickening of the left ventricle had already been during the first pregnancy, so that it is indeed possible that her hypercortisolism existed during the first pregnancy, resulting in the intra-uterine fetal death.

Cushing's syndrome remains a "killing disease" because of its cardiovascular complications even under non-pregnant conditions. Significant maternal morbidity is attributable to congestive heart failure [1, 2]. In this case, it was very difficult to control the congestive heart failure. Possible reasons for the congestive heart failure are: first, gross left ventricular hypertrophy induced a 
reduction in the compliance of the left ventricle; second, the hypercotisolism augmented the water load induced by pregnant condition.

Sugihara et al. reported that three cases in which left ventricular failure was the predominant feature were associated with gross left ventricular hypertrophy which was remarkably improved after adrenalectomy [6, 8]. In agreement with Sugihara et al., we observed a dramatic improvement in left ventricular hypertrophy and abnormality in the electrocardiography after the adrenalectomy and after the delivery. The mechanism(s) of left ventricular hypertrophy observed in patients with Cushing's syndrome remains unclear. Fallo et al. reported that as to left ventricular hypertrophy in the progression of the condition in Cushing's syndrome, it is thought that not only increased aortic pressure but excessive plasma cortisol may be etiologic factors [7]. Pregnancy induced acute physiological left ventricle hypertrophy transiently secondary to self-limited hemodynamic load [12, 13]. The degree of left ventricle hypertrophy in this case was more severe than that in the cases previously reported. We consider that our patient's progression of left ventricular wall-thickening may have been augmented by changes in her hemodynamic load rather than induced only by an excess of plasma cortisol.

Various recommendations have been made for the treatment of pregnant women with Cushing's syndrome. There were several reports stating that conservative treatment was successful in certain cases of Cushing's syndrome complicating pregnancy $[7,14-16]$, whereas a number of reports recommended surgical treatment $[9,17,18]$. In the second trimester of pregnancy, surgical treatment has been recommended for patients with severe hypercortisolism, but conservative treatment was recommended for patients with mild hypercortisolism [9]. The level of plasma cortisol in this case was high enough to elicit a severe infection such as sepsis and meningitis. We found an abnormality in electrocardiography in this case, which was in agreement with the report that the level of cortisol was associated with such a finding in Cushing's syndrome [19]. We speculated that the association may reflect the progression of left ventricular hypertrophy induced by severe hypercortisolism. Furthermore, the prevalence of adrenocortical carcinoma in Cushing's syndrome increased in pregnant patients [20]. We therefore decided on a left adrenalectomy for Cushing's syndrome in the pregnant patient under study.

\section{References}

1. Buescher MA, McClamrock HD, Adashi EY (1992) Cushing syndrome in pregnancy. Obstet Gynecol 79: 130-137.

2. Martin RW, Lucas JA, Martin JN Morrison JC, Cowan BD (1989) Conservative management of Cushing's syndrome in pregnancy. A case report. J Reprod Med 34: 493-495.

3. Pickard J, Jochen AL, Sadur CN, Hofeldt FD (1990) Cushing's syndrome in pregnancy. Obstet Gynecol Surv 45: 87-93.

4. Younge PA, Schmidt D, Wiles PG (1995) Cushing's syndrome: Still a potential killing disease. $J R$ Soc Med 88: 174-175.

5. Molitch ME (1992) Endocrine emergency in pregnancy. Baillieres Clin Endocrinol Metab 6: 167191.

6. Sugihara N, Shimizu M, Kita Y, Shimizu K, Ino H, Miyamori I, Nakabayashi H, Takeda R (1992) Cardiac characteristics and postoperative course in Cushing's syndrome. Am J Cardiol 69: 1475-1480.

7. Fallo F, Budano S, Sonino N, Muiesan ML,
Agabiti-Rosei E, Boscaro M (1994) Left ventricular structural characteristics in Cushing's syndrome. J Hum Hypertens 8: 509-513.

8. Sugihara N, Shimizu $M$, Shimizu K, Ino $H$, Miyamori I, Nakabayashi H, Takeda R (1992) Disproportionate hypertrophy of the inter ventricular septum and its regression in Cushing's syndrome. Report of three cases. Intern Med 31: 407413.

9. Nakayama T, Soma M, Kubo A, Matsuoka M, Abe Y, Ito M, Watanabe Y, Izumi Y, Yasugi T (1992) Pregnancy in Cushing's syndrome. Folia Endocrinol Japon 68: 1130-1149 (In Japanese).

10. Fantl VE, Wang DY, Mockridge CI (1988) Measurement of human corticosteroid binding globulin by enzyme-linked immunoassay. J Steroid Biochem 31: 187-193.

11. Carr BR, Parker Jr CR, Madden JD, MacDonald PC, Porter JC (1981) Maternal plasma adrenocorticotropin and cortisol relationships throughout human pregnancy. Am J Obstet Gynecol 139: 416- 
422.

12. Grossman W, Jones D, MacLaurin LP (1975) Wall stress and pattern of hypertrophy in the human left ventricle. J Clin Invest 56: 56-64.

13. Mone SM, Sanders SP, Colan SD (1996) Control mechanisms for physiological hypertrophy of pregnancy. Circulation 15: 667-672.

14. Close CF, Mann MC, Watts JF, Tailor KG (1993) ACTH-independent Cushing's syndrome in pregnancy with spontaneous resolution after delivery: Control of hyper cortisolism with metyrapone. Clin Endocrinol 39: 375-379.

15. Divers MJ (1990) Ketoconazole treatment of Cushing's syndrome in pregnancy. Am J Obstet Gynecol 163: 1101.

16. Amado JA, Pesquera C, Gonzalez EM, Otero M, Freijanes J, Alvarez A (1990) Successful treatment with ketoconazole of Cushing's syndrome in pregnancy. Postgrad Med J 66: 221-223.

17. Pricolo VE, Monchik JM, Prinz RA, DeJong S, Chadwick DA, Lamberton RP (1990) Management of Cushing's syndrome secondary to adrenal adenoma during pregnancy. Surgery 108: 1072-1078.

18. Aron DC, Schnall AM, Sheeler LR (1990) Cushing's syndrome and pregnancy. Am J Obstet Gynecol 162: 244-252.

19. Bevan JS, Gough MH, Gillmer MD, Burke CW (1987) Cushing's syndrome in pregnancy: The timing of definitive treatment. Clin Endocrinol 27: 225-233.

20. Tsuda K, Saikawa T, Yonemochi H, Maeda T, Shimoyama N, Hara M, Ito Y, Sakata T (1995) Electrocardiographic abnormalities in patients with Cushing syndrome. Jpn Heart J 36: 333-339. 